\title{
EDITORIAL
}

\section{Still waiting after all these years}

\author{
Christopher S Simpson MD
}

C anadians understand that when they require nonemergent health care, they will usually have to wait. They wait in emergency rooms, they wait for diagnostic tests, they wait to see specialists, and they wait for surgery and procedures. Often, they even wait to get out of hospitals. When waits are appropriately brief, patients feel confident and satisfied. When waits are too long, however, patients and their families experience anxiety, economic hardship, needless pain and suffering, and perhaps even more serious adverse events, including death.

A tremendous amount of effort and resources have been poured into the wait time dilemma over the past five years. Medical professional groups have developed evidence-based wait time benchmarks (1). The Canadian Medical Association's Wait Time Alliance, of which the Canadian Cardiovascular Society (CCS) is a founding member, has been particularly active in advancing this issue on the national stage. Their annual report cards on wait times in Canada have served as a central lightning rod in the national debate (2). Provincial and territorial governments have worked diligently to better understand and reduce wait times for surgical procedures through improved data collection and targeted spending.

Undoubtedly, there have been improvements. In Ontario, for example, meaningful reductions in wait times for cataract surgery, joint replacement, cancer surgery and diagnostic imaging have been demonstrated (3). Other provinces have also seen improvements in a limited number of targeted priorities (4).

Why then, are patients, providers and payers still underwhelmed? Why are so many Canadians still dissatisfied with their experience in the health care system?

In the present issue of The Canadian Journal of Cardiology, Légaré et al (5) have hit the nail on the head. The authors have found that when they step into patients' shoes and look at the whole health care experience from the patients' eyes, a very different picture emerges from the one painted by conventionally determined and reported surgical wait times. They have shown that the wait time for cardiac surgery in Nova Scotia underestimates the true wait, as seen and experienced by the patient, because the wait time is defined as beginning on the date when a decision is made to perform the surgical procedure. While this definition is broadly accepted and widely applied, not only in the cardiac literature, but in the surgical literature in general, largely because it is intuitive and easy to measure, the surgical wait is, in fact, only one of many pieces of the continuum of care that comprise the patient's total health care experience. The surgical wait time is, of course, only one component of the patient's journey through a series of clinical, consultative, diagnostic and therapeutic events spanning symptom onset to recovery.

The authors hint at the complexity and interdependencies of the processes that characterize and define the patient's journey by pointing out that these cardiac surgical patients first had to access the system with a symptom or syndrome, either through the emergency room or via a primary health care provider, and then have a coronary angiogram, followed by additional testing and consultations. They have also shown us how attention to these other components of the journey can inform us about pressure points in the continuum. For example, in this series, initial presentation through the emergency room led to a more prompt angiographic evaluation and faster surgery than did presentation to a family doctor. Findings like these allow us to better understand the system's bottlenecks in patient flow. After all, it is at these bottlenecks where negative perceptions, inequities and, potentially, suboptimal outcomes are born. It is also where inefficiency and waste are generated. The Canadian Medical Association estimates that waits exceeding medically acceptable benchmarks in just four key procedures cost our economy $\$ 14.8$ billion in 2007 (6).

\section{Ballooning}

One of the criticisms of the recent focus on wait times in the five 'priority areas' (cancer, cardiac, diagnostic imaging, sight restoration and joint replacements) has been that, although these are worthy areas on which to expend effort and resources, doing so only redistributes the pressure elsewhere, like squeezing a balloon. This 'ballooning effect', it is said, creates victories for the priority areas, necessarily at the expense of lower profile surgical procedures. Although evidence is lacking, this is likely at least partially true - in many provinces, hospitals have been given additional funds to meet wait time targets in key areas, but no infrastructure money to increase the number of operating suites available. The only possible outcome in this scenario, barring acting on a previously unrecognized efficiency opportunity, is for some 'nonpriority' procedural volumes to contract to allow others to increase. There are numerous anecdotal examples of this rationing phenomenon.

Similarly, a focus on only the traditional wait time definition for cardiac surgery, or any surgical procedure for that matter, fails to take into account the potential impact of the other components of that same patient's health care journey. If the surgeon is doing more surgical procedures, thereby shortening the surgical wait times, the consequence may be less availability of the surgeon to see patients in preoperative clinics. If the 'upstream' wait list - that is, the time it takes to see a surgeon in the first place - grows, specifically because the surgical wait time has decreased, has the patient really gained anything? A broader definition of wait times, as the authors suggest, would help to determine whether this ballooning phenomenon occurs at the intrapatient journey level as well.

All of the components of the patient journey are equally important from a total patient experience point of view. It is the sum of these components that is the major measurement of interest. The time stamps attached to the start and conclusion of each constituent component provide us with information we need to inform system improvement processes, but as stand-alone measures, these traditional surgical wait time definitions have less clinical value than we would like to believe.

\section{Patient navigation}

The other reality of the patient journey that is commonly underappreciated is the often disjointed nature of all its constituent parts. Consider the following hypothetical, but representative scenario:

A patient with chest pain presents to an emergency department in a town of 20,000 people, where she sees the duty emergency room physician. Myocardial infarction is ruled out, so the patient is discharged with plans for an outpatient stress test. The

\footnotetext{
Division of Cardiology, Queen's University; Cardiac Program, Kingston General Hospital and Hotel Dieu Hospital, Kingston, Ontario; Canadian

Cardiovascular Society Committee on Access to Care

Correspondence: Dr Christopher S Simpson, Kingston General Hospital/Hotel Dieu Hospital, 76 Stuart Street, FAPC Level 3, Kingston, Ontario

K7L 2V7. Telephone 613-549-6666 ext 3377, fax 613-548-1387, e-mail simpsonc@kgh.kari.net
}

Received for publication August 4, 2009. Accepted August 9, 2009 
test, performed two weeks later, is supervised by an internist, who interprets it as positive. The report is sent to the patient's family physician, who receives and reviews the report one week later.

The family physician then calls the patient to come and see her. One week later, the family physician sees the patient, tells her the stress test is positive and refers her to a local internist. The internist sees the patient three weeks later and, in turn, refers the patient to an interventional cardiologist located in a city $3 \mathrm{~h}$ away. The interventionalist sees the patient in a precatheterization clinic four weeks later, and books the patient for an angiogram in another two weeks. Two weeks later, the patient drives back, only to have the appointment cancelled because of emergencies that day. The procedure is rebooked for one week later. The patient then has the angiogram, threevessel coronary disease is diagnosed, and a referral is made to a cardiac surgeon. The surgeon sees the patient in a clinic two weeks later, and places the patient on the surgical wait list. Coronary artery bypass graft surgery occurs six weeks later. The patient is discharged in one week, and is put on a wait list for cardiac rehabilitation. Four weeks following discharge, she attends her first session, and completes it 12 weeks later.

This patient's wait time for cardiac surgery would be entered into the books as six weeks. But from the patient's perspective, we can see that the wait time was actually 22 weeks from symptom onset to cardiac surgery, and then an additional 17 weeks until the end of cardiac rehabilitation. We also get a sense of the potential for loose continuity of care (seven physicians were involved in her care), and the anxieties and uncertainties that would surely accompany such a convoluted journey from symptom onset to recovery.

A process that acknowledged and measured this journey in its totality, that was geared to navigate or coordinate patients through the 'system', and that provided transparent expectations about what constitutes reasonable and safe waits for each component, would provide peace of mind for the patient (knowing that she was being 'managed' through a continuum rather than shuffled from one component to another), allow for real-time monitoring of the entire experience so that pressure points could be attended to in a timely way, and allow for more meaningful comparisons of patient experiences in different political jurisdictions or geographical areas. Resource managers would be able to more confidently redirect funds and other resources to the precise point in the continuum that contributes to the excessive wait. Finally, opportunities to carry out processes in parallel rather than in series, or to skip unnecessary or inappropriate steps, would be more readily apparent with a 'macro' view of the entire journey.

\section{Moving forward}

Much has been accomplished since 2004, when the First Ministers determined that wait times in Canada needed to be addressed. Among the notable achievements to date has been the development of national, pan-continuum wait time benchmarks for most medical tests and treatments. The CCS was the first specialty society out of the gate with their benchmarks, which were published in 2005 (7). The CCS was also the first specialty society to advance the concept of the patient journey in the access to care context.

Work like that of Légaré et al is important, not just for the new information we have learned about cardiac surgery patients in Nova Scotia, but for the cultural change that it helps facilitate. Our efforts must be directed toward patients, not procedures. The next step is for an investment in data collection and information management systems that can properly measure and compare patients' experiences in our health care system across the entire continuum. Only with solid data can we begin to understand the barriers to timely access, use our resources to achieve optimal outcomes, and build a health care system that is worthy of Canadians' confidence and trust.

\section{REFERENCES}

1. Wait Time Alliance for Timely Access to Health Care. <http://www. waittimealliance.ca/wait_times.htm $>$ (Version current at November 10, 2009).

2. Wait Time Alliance. Unfinished business. Report Card on Wait Times in Canada. <http://www.waittimealliance.ca/June2009/Report-cardJune2009_e.pdf> (Version current at November 10, 2009).

3. Ministry of Health and Long-Term Care. Ontario Wait Times. <http:// www.health.gov.on.ca/transformation/wait_times/wait_mn.html> (Version current at November 10, 2009).

4. Health Canada. Wait Times in Canada. <http://www.hc-sc.gc.ca/hcssss/qual/acces/wait-attente/index-eng.php > (Version current at November 10, 2009).

5. Légaré J-F, Li D, Buth KJ. How established wait times benchmarks significantly underestimate total wait times for cardiac surgery. Can J Cardiol 2010;26:e17-21.

6. The Centre for Spatial Economics. The economic cost of wait times in Canada. <http://www.cma.ca/multimedia/CMA/Content_Images/ Inside_cma/Media_Release/pdf/2008/EconomicReport.pdf $>$ (Version current at November 10, 2009).

7. Canadian Cardiovascular Society. Universal Access, but When? Treating the Right Patient at the Right Time. Wait Time Benchmarks For Cardiovascular Services And Procedures. < http://ccs.ca/download/ position_statements/CCS_Atlas_for_CCS.pdf $>$ (Version current at November 10, 2009). 